\title{
OPTIMASI PRODUKSI CRUMB RUBBER DENGAN MENGGUNAKAN LINEAR PROGRAMMING
}

\author{
Vera Devani, Putri Kartika \\ Program Studi Teknik Industri, Fakultas Sains dan Teknologi \\ Universitas Islam Negeri Sultan Syarif Kasim Riau \\ e-mail: veradevani@gmail.com
}

\begin{abstract}
ABSTRAK
PT. PPB merupakan perusahaan yang bergerak di bidang industri karet. Perusahaan tersebut memproduksi crumb rubber SIR 10 dan crumb rubber SIR 20. Metode yang digunakan pada penelitian ini adalah Linear Programming. Linear programming adalah merupakan suatu metode penyelesaikan solusi optimum dengan memperhatikan pengalokasian sumber daya yang tersedia. Dari hasil penelitian dapat diperoleh keuntungan optimal perusahaan untuk satu kali produksi sebesar Rp 69.473.690,- dan perusahaan mampu memproduksi produk crumb rubber SIR 10 sebesar 1,05 kali produksi dalam satu hari. Kebutuhan waktu setiap proses produksi adalah pencucian 1,05 jam, pemecahan 1,76 jam, penggilingan 2,63 jam, pengeringan 454,72 jam, dan packing 1,05 jam. Kebutuhan bahan baku 33,68 ton dan tenaga kerja 40 orang. Berdasarkan analisis sensitivitas diperoleh bahwa perubahan yang dilakukan terhadap solusi optimum masih berada pada nilai tolerasi yang ditetapkan oleh perusahaan.
\end{abstract}

Kata kunci: Analisis Sensitivitas, Crumb Rubber, Linear Programming, Optimasi.

\begin{abstract}
PT. PPB is a company engaged in the rubber industry. The company manufactures crumb of SIR 10 and crumb rubber of SIR 20. The method used in this research is Linear Programming. Linear programming is a method of completion of optimum solution with respect to allocating available resources. From the results of the research can be obtained the company's optimal benefit for one-time production of $R p$ 69,473,690 and the company is able to manufacture the product crumb rubber of SIR 10 amounting to 1.05 times the production in one day. The necessity of each production process is 1.05 hours of washing, 1.76 hour solution, 2.63 hour milling, 454.72 hour drying, and packing 1.05 hours. Raw material needs 33.68 tons and labor 40 people. Based on sensitivity analysis is obtained that the changes made to the optimum solution are still at the toleration value set by the company.
\end{abstract}

Keywords: Crumb Rubber, Linear Programming, Optimization, Sensitivity Analysis.

\section{PENDAHULUAN}

Persaingan dalam sektor industri karet pada saat ini mengalami pertumbuhan yang sangat pesat. Indonesia merupakan negara yang memiliki prospek yang sangat menjanjikan di bidang industri karet. Dalam bidang ini banyak pengusaha maupun investor asing menanamkan modalnya pada industri karet. Hal ini disebabkan karena produk yang dihasilkan dari karet sangat bervariasi, di samping itu harga bahan baku murah juga sangat mudah untuk didapat. Sebagai salah satu komoditi industri, produksi karet sangat tergantung pada teknologi dan manajemen yang diterapkan dalam sistem dan proses produksinya.

PT. PPB merupakan perusahaan yang bergerak di bidang industri karet yang mengolah bahan baku karet yang berasal dari petani karet menjadi produk setengah jadi (crumb rubber). PT. PPB memproduksi crumb rubber SIR (Standard Indonesia Rubber) 10 dan SIR (Standard Indonesia Rubber) 20. Perusahaan mengambil keputusan mengenai penentuan jumlah produksi berdasarkan permintaan dari konsumen dan belum mengetahui teknik pengalokasian sumber daya yang menghasilkan jumlah produksi yang optimal agar memperoleh pendapatan yang maksimal. PT. PPB perlu merubah cara pengambilan keputusan mengenai alokasi sumber daya produksi dengan mengalokasikan sumber daya yang tersedia dengan untuk menghasilkan pendapatan yang optimal. 
Penelitian sebelumnya yang menggunakan metode Linear Programming sudah banyak dilakukan. Penelitian yang dilakukan oleh Tansel [1] tentang pengembangan model alokasi batas kredit bank menggunakan integrasi Fuzzy TOPSIS dan Linear Programming. Pada penelitian ini, dibuat sebuah model alokasi dengan konstrain resiko kredit yang dikembangkan oleh bank untuk menentukan konstrain risiko kredit dari kepala regional. Linear Programming menggabungkan hasil Fuzzy TOPSIS, konstrain dan fungsi tujuan yang ditetapkan oleh bank.

Penelitian yang dilakukan oleh Chang [2] mengenai integrasi pembangkit listrik dan perencanaan grid lintas batas untuk pasar listrik ASEAN menggunakan Linear Programming. Studi ini membangun model Linear Programming yang dinamis dan mensimulasikan jalur pengembangan kapasitas pembangkit listrik yang optimal di negara ASEAN. Berdasarkan skenario yang dibangun ditemukan bahwa lebih banyak perdagangan tenaga terbuka mendorong pengembangan sumber terbarukan pembangkit listrik, dan menghasilkan lebih banyak simpanan biaya total memenuhi permintaan daya masa depan yang semakin meningkat dari 2010 ke 2030.

Harianto [3], melakukan penelitian tentang penerapan Linear Programming di Industri Tekstil. Berdasarkan penelitiannya diperoleh produk benang dan kain tenun dapat diproduksi secara optimal dengan laba bisnis mencapai US \$ 235.000.

Penelitian yang dilakukan oleh Aprilyanti [4], tentang penerapan Linear Programming untuk mengoptimalkan keuntungan produksi Kemplang. Dengan menggunakan Metode Simpleks terjadi peningkatan keuntungan penjualan menjadi Rp. 617.550,- jika produksi pada Kemplang Lidah Badak ditingkatkan sebanyak 3 kali dari sebelumnya.

Penelitian yang dilakukan adalah optimasi produksi crumb rubber SIR 10 dan SIR 20. Pada penelitian ini akan ditentukan keuntungan optimal, kebutuhan waktu setiap proses produksi, kebutuhan tenaga kerja dan kebutuhan bahan baku untuk SIR 10 dan SIR 20 serta dilakukan analisis sensitivitas terhadap solusi optimum yg dicapai.

Menurut SNI 06-1903-2000 Standard Indonesia Rubber (SIR), bahan baku lateks cair diolah menjadi SIR $3 \mathrm{CV}$, SIR 3 L, SIR 3 WF. Jika bahan baku lateks dibekukan (koagulum lateks), maka bahan baku tersebut dapat diolah menjadi SIR 5. Jika bahan baku lateks terkoagulasi di lapangan (dinamakan lump), maka bahan baku lump dapat diolah menjadi SIR 10 dan SIR 20. SIR 3 dengan spesifikasi CV (Constant Viscosity) 50 memiliki arti bahwa crumb rubber tersebut memiliki kadar kotoran $0,03 \%$ dan batasan viscositas money antara 45-55. SIR 3 dengan spesifikasi CV 60 memiliki arti bahwa crumb rubber tersebut memiliki kadar kotoran 0,03\% dan batasan viscositas money antara 56-65. SIR 10 tidak memiliki standar Constant Viscosity (CV).

Model-model Operation Research merupakan teknik penyelesaian terhadap sebuah persoalan matematis yang akan menghasilkan solusi optimal. Di dalam Operation Research, keputusan optimal dari sebuah model mungkin merupakan keputusan terbaik bagi keadaan nyata, namun mungkin juga bukan [5]. Optimasi merupakan pemilihan alternatif yang terbaik dari beberapa pilihan

Menurut Dantzig [6], Linear Programming adalah memaksimumkan atau meminimumkan suatu fungsi tujuan linear dengan beberapa variabel pembatas persamaan dan pertidaksamaan linear. Linear Programming adalah sebuah metode matematis yang berkarakteristik linear untuk menemukan suatu penyelesaian optimal dengan cara memaksimumkan atau meminimumkan fungsi tujuan terhadap satu susunan kendala [7]. Definisi lain, Liniear Programming merupakan salah satu teknik yang dapat membantu dalam pengambilan keputusan alokasi sumber daya yang terbatas dan langka secara optimum dimana sumber daya terbatas tersebut meliputi semua faktor-faktor produksi seperti; mesin-mesin, tenaga kerja, bahan mentah, modal, teknologi dan informasi [8]. 
Berdasarkan definisi di atas dapat disimpulkan bahwa Linear Programming adalah merupakan teknik optimasi pengalokasian sumber daya yang tersedia untuk mengoptimalkan fungsi tujuan (memaksimumkan atau meminimumkan) pada sebuah fungsi tujuan linier dengan fungsi kendala persamaan dan pertidaksamaan linier.

Fungsi dari Analisis Sensitivitas adalah untuk melakukan interpretasi dalam suatu pencapaian yang telah selesai. Dalam hal ini penyelesaian yang pada mulanya bersifat statis dalam menyelesaikan persoalan linier berubah menjadi alat dinamis yang berguna untuk mengevaluasi perubahan situasi [9]. Analisa Sensitivitas atau kepekaan adalah analisis yang dilakukan untuk mengetahui akibat/pengaruh dari perubahan yang terjadi pada parameter-parameter terhadap solusi optimal yang telah dicapai [10].

\section{METODE PENELITIAN}

Langkah-langkah dalam pengolahan data adalah sebagai berikut:

1. Menentukan variabel keputusan. Variabel keputusan yang digunakan adalah jenis produksi crumb yaitu:

$\mathrm{X}_{1}=\mathrm{SIR} 10$

$\mathrm{X}_{2}=$ SIR 20

2. Menentukan fungsi tujuan, yaitu memaksimumkan keuntungan.

3. Menentukan pembatas/kendala.

Kendala yang digunakan pada penelitian ini adalah waktu yang diperlukan pada setiap tahapan proses produksi (pencucian, pemecahan, penggilingan, pengeringan dan packing) untuk SIR 10 dan SIR 20, kebutuhan tenaga kerja dan bahan baku.

4. Menentukan solusi optimum model Linear Programming dengan menggunakan software QM for Windows 5.

5. Melakukan analisis terhadap solusi optimum menggunakan analisis sensitivitas.

a. Perubahan koefisien fungsi tujuan untuk Variabel Non Basis

b. Perubahan koefisien fungsi tujuan untuk Variabel Basis

c. Perubahan kolom untuk suatu Variabel Non Basis

d. Perubahan pada ruas kanan suatu pembatas

\section{HASIL DAN PEMBAHASAN}

Model Linear Programming untuk optimasi produksi crumb rubber adalah: Maksimumkan:

$$
\mathrm{Z}=66.000 .000 \mathrm{X}_{1}+44.000 .000 \mathrm{X}_{2}
$$

Berdasarkan pembatas:

$$
\begin{aligned}
X_{1}+1,16 X_{2} & \leq 2 \\
1,67 X_{1}+1,67 X_{2} & \leq 3 \\
2,5 X_{1}+2,5 X_{2} & \leq 4 \\
432 X_{1}+432 X_{2} & \leq 480 \\
X_{1}+X_{2} & \leq 1,5 \\
32 X_{1}+32 X_{2} & \leq 50 \\
38 \quad X_{1}+38 X_{2} & \leq 40 \\
X_{1}, X_{2} & \geq 0
\end{aligned}
$$

Solusi optimal model Linear Programming diperoleh dengan menggunakan software QM for Windows 5 adalah: 


\begin{tabular}{|c|c|c|c|c|c|c|c|c|c|c|c|}
\hline$\overline{C j}$ & Basic Variables & Quantity & $\begin{array}{r}6.6 E+07 \\
\text { Crumb Rubber SIR } 10\left(X_{1}\right)\end{array}$ & $\begin{array}{r}4.4 \mathrm{E}+07 \\
\text { Crumb Rubber SIR } 20(\mathrm{X} 2)\end{array}$ & $\begin{array}{r}0 \\
\text { slack } 1\end{array}$ & $\begin{array}{r}0 \\
\text { slack } 2\end{array}$ & $\begin{array}{r}0 \\
\text { slack } 3\end{array}$ & $\begin{array}{r}0 \\
\text { slack } 4\end{array}$ & $\begin{array}{r}0 \\
\text { slack } 5\end{array}$ & \begin{tabular}{|r|}
0 \\
slack 6
\end{tabular} & $\begin{array}{r}0 \\
\text { slack } 7\end{array}$ \\
\hline \multicolumn{12}{|l|}{ Iteration 1} \\
\hline 0 & slack 1 & 2 & 1 & 1,16 & 1 & 0 & 0 & 0 & 0 & 0 & 0 \\
\hline 0 & slack 3 & 4 & 2,5 & 2,5 & 0 & 0 & 1 & 0 & 0 & 0 & 0 \\
\hline 0 & slack 4 & 480 & 432 & 432 & 0 & 0 & 0 & 1 & 0 & 0 & 0 \\
\hline 0 & slack 5 & 1,5 & 1 & 1 & 0 & 0 & 0 & 0 & 1 & 0 & 0 \\
\hline \multirow[t]{3}{*}{0} & slack 7 & 40 & 38 & 38 & 0 & 0 & 0 & 0 & 0 & 0 & 1 \\
\hline & $z j$ & 0 & 0 & 0 & 0 & 0 & 0 & 0 & 0 & 0 & 0 \\
\hline & $c j-z j$ & & 66.000 .000 & 44.000 .000 & 0 & 0 & 0 & 0 & 0 & 0 & 0 \\
\hline \multicolumn{12}{|l|}{ Iteration 2} \\
\hline 0 & slack 1 & 0,9474 & 0 & 0,16 & 1 & 0 & 0 & 0 & 0 & 0 & $-0,0263$ \\
\hline 0 & slack 2 & 1,2421 & 0 & 0 & 0 & 1 & 0 & 0 & 0 & 0 & $-0,0439$ \\
\hline \multirow[t]{3}{*}{66000000} & Crumb Rubber SIR 10 (X1) & 1,0526 & 1 & 1 & 0 & 0 & 0 & 0 & 0 & 0 & 0,0263 \\
\hline & $z \mathrm{j}$ & & 66000000 & 66000000 & 0 & 0 & 0 & 0 & 0 & 0 & 1736842,0 \\
\hline & $c j-z j$ & & 0 & -22.000 .000 & 0 & 0 & 0 & 0 & 0 & 0 & \\
\hline
\end{tabular}

Gambar 1. Iterasi Linear Programming

\begin{tabular}{|l|r|r|}
\hline & \multicolumn{3}{|c|}{} \\
\hline Variable & Status & Value \\
\hline Crumb Rubber SIR 10 $(\mathrm{X} 1)$ & Basic & 1,0526 \\
\hline Crumb Rubber SIR 20 $(\mathrm{X} 2)$ & NONBasic & 0 \\
\hline slack 1 & Basic &, 9474 \\
\hline slack 2 & Basic & 1,2421 \\
\hline slack 3 & Basic & 1,3684 \\
\hline slack 4 & Basic & 25,2632 \\
\hline slack 5 & Basic &, 4474 \\
\hline slack 6 & Basic & 16,3158 \\
\hline slack 7 & NONBasic & 0 \\
\hline Optimal Value $(\mathrm{Z})$ & & 69473690 \\
\hline
\end{tabular}

Gambar 2. Solution List Linear Programming

Berdasarkan solusition list diperoleh PT. PPB harus memproduksi Crumb Rubber SIR 10 sebesar 1,05 kali produksi dengan keuntungan optimal Rp 69.473.690. Kebutuhan waktu pencucian 1,05 jam, pemecahan 1,76 jam, penggilingan 2,63 jam, pengeringan 454,72 jam, packing 1,05 jam, bahan baku 33,68 ton dan tenaga kerja 40 orang setiap produksi dalam satu hari.

\section{Analisis Sensitivitas}

Berdasarkan Gambar 1 dapat didefinisikan sebagai berikut:

$\mathrm{BV}=\left\{\mathrm{X}_{1}, \mathrm{~S}_{1}, \mathrm{~S}_{2}, \mathrm{~S}_{3}, \mathrm{~S}_{4}, \mathrm{~S}_{5}, \mathrm{~S}_{6}\right\}$

$\mathrm{NBV}=\left\{\mathrm{X}_{2}, \mathrm{~S}_{7}\right\}$

$$
\mathrm{X}_{\mathrm{BV}}=\left[\begin{array}{c}
S 1 \\
S 2 \\
S 3 \\
S 4 \\
S 5 \\
S 6 \\
X 1
\end{array}\right] ; \mathrm{X}_{\mathrm{NBV}}=\left[\begin{array}{c}
X 2 \\
S 7
\end{array}\right]
$$

Variabel Basis yaitu $X_{1}, S_{1}, S_{2}, S_{3}, S_{4}, S_{5}, S_{6}$ dan Variabel Non Basis adalah $X_{2}, S_{7}$.

$$
\mathrm{B}^{-1}=\left[\begin{array}{lllllll}
1 & 0 & 0 & 0 & 0 & 0 & -0,0263 \\
0 & 1 & 0 & 0 & 0 & 0 & -0,0439 \\
0 & 0 & 1 & 0 & 0 & 0 & -0,0658 \\
0 & 0 & 0 & 1 & 0 & 0 & -11,3684 \\
0 & 0 & 0 & 0 & 1 & 0 & -0,0263 \\
0 & 0 & 0 & 0 & 0 & 1 & -0,08421 \\
0 & 0 & 0 & 0 & 0 & 0 & 0,0263
\end{array}\right]
$$




\section{Analisis Terhadap Perubahan Koefisien Fungsi Tujuan Variabel Non Basis}

Variabel non basis adalah $\mathrm{X}_{2}$ yaitu produk Crumb Rubber SIR 20. Koefisien fungsi tujuan $\mathrm{X}_{2}$ saat ini adalah $\hat{\mathrm{c}}_{2}=44.000 .000$. Jika $\hat{\mathrm{c}}_{2}$ berubah, dari 44.000 .000 menjadi $(44.000 .000+\Delta)$. Perubahan ini dilakukan untuk mendapatkan keuntungan yang besar dengan cara menurunkan jumlah produksi crumb rubber SIR 20 untuk meningkatkan produksi crumb rubber SIR 10 karena proses produksi dan jumlah tenaga kerja yang dibutuhkan sama.

$$
\begin{aligned}
\mathrm{C}_{\mathrm{BV}} \mathrm{B}^{-1}= & {\left[\begin{array}{lllllll}
0 & 0 & 0 & 0 & 0 & 0 & 66.000 .000
\end{array}\right]\left[\begin{array}{ccccccc}
1 & 0 & 0 & 0 & 0 & 0 & -0,0263 \\
0 & 1 & 0 & 0 & 0 & 0 & -0,0439 \\
0 & 0 & 1 & 0 & 0 & 0 & -0,0658 \\
0 & 0 & 0 & 1 & 0 & 0 & -11,3684 \\
0 & 0 & 0 & 0 & 1 & 0 & -0,0263 \\
0 & 0 & 0 & 0 & 0 & 1 & -0,08421 \\
0 & 0 & 0 & 0 & 0 & 0 & 0,0263
\end{array}\right] } \\
& =\left[\begin{array}{llllllll}
0 & 0 & 0 & 0 & 0 & 0 & 0 & 1.735 .800
\end{array}\right]
\end{aligned}
$$

Perubahan koefisien Variabel Non Basis yang menyebabkan Variabel Basis tetap optimal adalah:

$$
\begin{aligned}
\hat{c}_{2} & =\left[\begin{array}{lllllll}
0 & 0 & 0 & 0 & 0 & 0 & 1.735 .800
\end{array}\right]\left[\begin{array}{c}
1,6 \\
1,67 \\
2,5 \\
432 \\
1 \\
34 \\
38
\end{array}\right]-(44.000 .000+\Delta) \\
& =-21.960 .400-\Delta
\end{aligned}
$$

Berdasarkan perhitungan diperoleh agar $\hat{\mathrm{c}}_{2} \geq 0$ dan $\mathrm{BV}$ tetap optimal, jika $\Delta \leq$ -21.960.400. Dengan kata lain, batas toleransi keuntungan yang diperbolehkan agar solusi tetap optimal untuk SIR 20 adalah Rp 22.039.600,-

\section{Analisis Terhadap Perubahan Koefisien Fungsi Tujuan Variabel Basis}

Mengubah koefisien fungsi tujuan Variabel Basis artinya mengubah $\mathrm{C}_{\mathrm{BV}}$ sehingga beberapa koefisien pada baris 0 dari tabel optimal akan berubah. Koefisien fungsi tujuan yang akan diubah adalah $\hat{c}_{1}, \hat{c}_{1}$ berubah dari 66.000.000 menjadi $(66.000 .000+\Delta)$, perubahan ini terjadi disebabkan karena banyaknya permintaan. Hal inilah yang mempengaruhi perubahan pada fungsi tujuan Variabel Basis dengan tujuan untuk memaksimumkan laba. Maka $\mathrm{C}_{\mathrm{BV}}$ yang baru adalah $\left[\begin{array}{lllllllll}0 & 0 & 0 & 0 & 0 & 0 & 66.000 .000 & +\Delta\end{array}\right]$ sehingga:

$$
\begin{aligned}
\mathrm{C}_{\mathrm{BV}} \mathrm{B}^{-1} & =\left[\begin{array}{lllllll}
0 & 0 & 0 & 0 & 0 & 0 & 66.000 .000+\Delta
\end{array}\right]\left[\begin{array}{ccccccc}
1 & 0 & 0 & 0 & 0 & 0 & -0,0263 \\
0 & 1 & 0 & 0 & 0 & 0 & -0,0439 \\
0 & 0 & 1 & 0 & 0 & 0 & -0,0658 \\
0 & 0 & 0 & 1 & 0 & 0 & -11,3684 \\
0 & 0 & 0 & 0 & 1 & 0 & -0,0263 \\
0 & 0 & 0 & 0 & 0 & 1 & -0,08421 \\
0 & 0 & 0 & 0 & 0 & 0 & 0,0263
\end{array}\right] \\
& =\left[\begin{array}{lllllll}
0 & 0 & 0 & 0 & 0 & 0 & 1.735 .800+0,0263 \Delta
\end{array}\right]
\end{aligned}
$$


Koefisien baris 0 menjadi:

a. $\quad \hat{\mathrm{c}}_{2}=\mathrm{C}_{\mathrm{BV} \mathrm{B}} \mathrm{B}^{-1} \mathrm{a}_{2}-\mathrm{c}_{2}$

$$
\begin{aligned}
& =\left[\begin{array}{lllllll}
0 & 0 & 0 & 0 & 0 & 0 & 1.735 .800+0,0263 \Delta
\end{array}\right]\left[\begin{array}{c}
1,6 \\
1,67 \\
2,5 \\
432 \\
1 \\
34 \\
38
\end{array}\right]-44.000 .000 \\
& =21.960 .400+0,9994 \Delta
\end{aligned}
$$

b. $\mathrm{S}_{7}=\mathrm{C}_{\mathrm{BV}} \mathrm{B}^{-1} \mathrm{a}_{7}-\mathrm{c}_{7}$

$$
\begin{aligned}
& =\left[\begin{array}{lllllll}
0 & 0 & 0 & 0 & 0 & 0 & 1.735 .800+0,0263 \Delta
\end{array}\right]\left[\begin{array}{l}
0 \\
0 \\
0 \\
0 \\
0 \\
0 \\
1
\end{array}\right]-0 \\
& =1.735 .800+0,0263 \Delta
\end{aligned}
$$

Solusi basis akan tetap optimal sepanjang $\Delta \geq-21.973 .584$. Artinya jika $\mathrm{c}_{1}$ naik sebesar -21.973.584, maka solusi basis saat ini akan tetap optimal. Dengan kata lain batas toleransi keuntungan yang diperbolehkan agar solusi tetap optimal untuk SIR 10 adalah Rp 44.026.416,-

\section{Analisis Terhadap Perubahan Ruas Kanan Pembatas}

Perubahan pada ruas kanan dilakukan pada jumlah tenaga kerja. Berdasarkan pengamatan di lapangan pada saat proses produksi ada pekerja yang tidak bekerja sesuai dengan tugasnya, sehingga diperlukan pengurang untuk memaksimalkan kinerja para pekerja dan dapat mengurangi biaya tenaga kerja. Maka $b_{7}$ berubah dari 40 orang tenaga kerja, menjadi $(40+\Delta)$, sehingga ruas kanan menjadi:

$$
\mathrm{B}^{-1} \mathrm{~b}=\left[\begin{array}{ccccccc}
1 & 0 & 0 & 0 & 0 & 0 & -0,0263 \\
0 & 1 & 0 & 0 & 0 & 0 & -0,0439 \\
0 & 0 & 1 & 0 & 0 & 0 & -0,0658 \\
0 & 0 & 0 & 1 & 0 & 0 & -11,3684 \\
0 & 0 & 0 & 0 & 1 & 0 & -0,0263 \\
0 & 0 & 0 & 0 & 0 & 1 & -0,08421 \\
0 & 0 & 0 & 0 & 0 & 0 & 0,0263
\end{array}\right]\left[\begin{array}{c}
2 \\
3 \\
4 \\
480 \\
1,5 \\
50 \\
40+\Delta
\end{array}\right]=\left[\begin{array}{c}
0,948-0,0263 \Delta \\
1,244-0,0439 \Delta \\
1,368-0,0658 \Delta \\
25,264-11,3684 \Delta \\
0,448-0,0263 \Delta \\
46,6316-0,08421 \Delta \\
1,052+0,0263 \Delta
\end{array}\right]
$$

Solusi basis saat ini akan tetap optimal jika:

$-40 \leq \Delta \leq 2,2223$ atau $0 \leq \mathrm{b}_{7} \leq 42,2223$. Solusi akan tetap optimal jika jumlah tenaga kerja maksimal adalah 43 orang.

\section{Analisis Terhadap Perubahan Kolom Variabel Non Basis}

Perubahan dilakukan dengan mengurangi jumlah tenaga kerja pada proses produksi karet serta menambahkan waktu produksi pada proses pembungkusan (packing). Pengurangan jumlah tenaga kerja dilakukan setelah melihat kondisi di lapangan, dimana 
karyawan banyak melakukan pekerjaan yang menganggur. Penambahan waktu pada proses packing karena proses pengerjaan yang manual sehingga memerlukan waktu lebih lama. Matrik berikut menunjukkan perubahan kolom Variabel Non Basis. Matrik kolom Variabel Non Basis awal:

$$
\mathrm{a}_{2}=\left[\begin{array}{c}
1,16 \\
1,67 \\
2,5 \\
432 \\
1 \\
32 \\
38
\end{array}\right]
$$

Maka kolom tersebut berubah menjadi:

$$
\mathrm{a}_{2}=\left[\begin{array}{c}
1,16 \\
1,67 \\
2,5 \\
432 \\
1,5 \\
32 \\
37
\end{array}\right]
$$

Jika $\hat{c}_{2} \geq 0$, maka solusi basis saat ini akan tetap optimal. Dengan berubahnya kolom a2, maka:

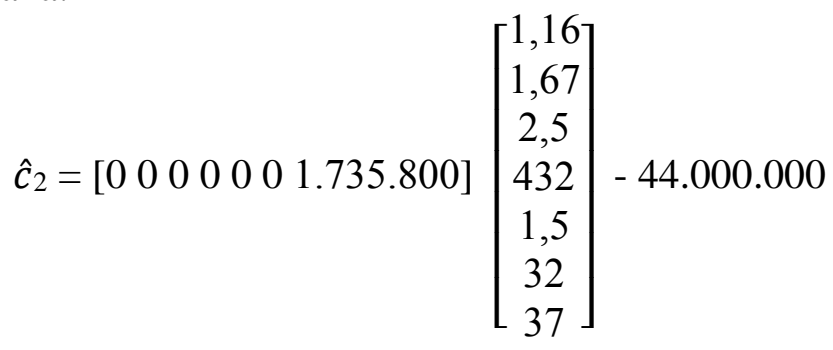$$
=20.224 .600
$$

Dengan mengurangi jumlah tenaga kerja solusi akan tetap optimal, keuntungan crumb rubber SIR 20 sebesar Rp 20.224.600.

\section{KESIMPULAN}

Keuntungan optimum yang diperoleh PT. PPB sebesar Rp 69.473.690 dengan memproduksi crumb rubber dimana crumb rubber SIR 10 sebanyak 1,05 kali produksi dalam sehari. Kebutuhan waktu pencucian 1,05 jam, pemecahan 1,76 jam, penggilingan 2,63 jam, pengeringan 454,72 jam, packing 1,05 jam, bahan baku 33,68 ton dan tenaga kerja 40 orang. Berdasarkan analisis sensitivitas diperoleh solusi akan tetap optimal jika: batas toleransi keuntungan yang diperbolehkan agar solusi tetap optimal untuk SIR 20 adalah Rp 22.039.600, batas toleransi keuntungan yang diperbolehkan agar solusi tetap optimal untuk SIR 10 adalah Rp 44.026.416, jumlah tenaga kerja optimal adalah 43 orang dan dilakukan pengurangan jumlah karyawan menjadi 38 orang serta waktu packing menjadi 1,5 jam.

\section{DAFTAR PUSTAKA}

[1] Tansel, Y. 2012. Development of a Credit Limit Allocation Model for Banks Using an Integrated Fuzzy TOPSIS and Linear Programming, Expert Systems with Applications, Elsevier, 39(5), pp. 5309-5316. 
[2] Chang, Y. and Yanfei Li. 2013. Power Generation and Cross-Border Grid Planning for The Integrated ASEAN Electricity Market: A Dynamic Linear Programming Model, Energy Strategy Reviews, 2(2), pp 153-160.

[3] Harianto, R.A. 2016. Penerapan Linear Program Dengan Metode Grafis Pada Industri Tekstil, ISSN STT No 759 SK/Dirjen/STT/80, 01(03), pp. 32-36.

[4] Aprilyanti, S., Pratiwi, I., \& Basuki, M. 2018. Optimasi Keuntungan Produksi Kemplang Panggang Menggunakan Linear Programming Melalui Metode Simpleks, Seminar dan Konferensi Nasional IDEC.

[5] Siswanto. 2007. Operations Research. Jakarta: Erlangga.

[6] Dantzig, G.B. \& Thapa, M.N. 1997. Linear Programming: Introduction, New York: Springer-Verlag.

[7] Meflinda, A. dan Mahyarni. 2011. Operation Research (Riset Operasi). Pekanbaru: UNRI PRESS.

[8] Syaifuddin, D.T. 2011. Riset Operasi (Aplikasi Quantitative Analysis for Management), Malang: Penerbit Percetakkan CV Citra Malang.

[9] Hayu, D.A., dan Endra, R.Y. 2004. Riset Operasional Konsep-Konsep Dasar, Jakarta: Rineka Cipta.

[10] Dimyati, T.T., dan Dimyati, A. 2006. Operations Research. Bandung: Sinar Baru, SNI 06-1903-2000 Standard Indonesian Rubber (SIR), Badan Standardisasi Nasional. 